\title{
LA IMAGINACIÓN EN MENORES DE CONTEXTOS EDUCATIVOS MARGINADOS
}

\author{
Desireé Lozano Santos y José Miguel García Ramírez. Universidad de Granada
}

Fecha de recepción: 30 de junio de 2014

Fecha de revisión: 5 de julio de 2014

Fecha de aceptación: 15 de julio de 2014

\section{Resumen}

Este estudio de investigación exploratoria se realiza en un contextos de situación socioeconómicamente precaria. Los participantes son menores escolarizados. El instrumento utilizado para medir la creatividad fue la Prueba de Imaginación Creativa, PIC-J. Posteriormente, se realizó una intervención de biblioterapia para mejorar la imaginación creativa, la transmisión de valores y la expresión de sentimientos de los menores que viven en contexto de riesgo psicosocial. Los datos muestran la necesidad de una intervención terciaria en este campo ya que los jóvenes presentan una clara deficiencia de imaginación narrativa, gráfica y en general de su creatividad. Se demuestra la influencia del contexto en la inhibición de la imaginación en los menores.

Palabras clave: biblioterapia, escucha, imaginación, creatividad

La lectura es una actividad que nos va acompañado a lo largo de la vida. Pero, no todas las personas tienen la misma accesibilidad a los recursos. Algunos investigadores se centran en la biblioterapia como instrumento para la transmisión de valores, emociones y/o sentimientos de los menores cuyo microsistema se sitúa en un contexto con riesgo de exclusión social. El uso de la literatura para poder generar algún tipo de cambio en el receptor ha sido denominado como biblioterapia. Se trata de una forma de tratamiento bastante reciente. Los investigadores la han referido como un medio eficaz para la recuperación de personas con algún tipo de dificultad (Alves, 1982).

Los elementos presentes en la biblioterapia son comparables con los de otras terapias. El contenido del libro es presentado como una experiencia que puede generar una identificación entre el lector y la persona que presenta el texto. Esta terapia no está limitada a libros, puede ser acompañada por material audiovisual, así como la lectura propiamente dicha, la capacidad literaria de los pacientes o cualquier otro tipo de documento. Siendo clave la selección del material, el cual debe ser elegido con mucha atención y cuidado, para poder responder a los gustos, nivel intelectual, tendencias e ideas del grupo. La selección de las lecturas deben llevar a los lectores al optimismo y alegría en las sesiones, evitando siempre la inhibición o depresión. Se buscan lecturas que ayuden a resolver sus problemas y a expresar sus sentimientos (Robinson, 2012).

El cuento proporciona una serie de beneficios para el desarrollo personal y que emanan de elementos, presentes en todos ellos, y que son: la propia historia narrada, el afecto que transmite el propio cuento o la persona que lo lee/o narra, la 
identificación de las niñas y los niños con la historia y los personajes y su evasión del mundo real y por último la posibilidad de, a través del cuento, comprender y modificar realidades vividas o sentidas. (Castaño, 2013)

La imaginación es una parte clave en el desarrollo infantil de los niños. Es imprescindible, rechazar esa tradicional oposición entre fantasía y realidad, en la que realidad significa lo que existe y fantasía aquello que no existe. Esa oposición no tiene sentido. Apareciendo una serie de interrogantes: ¿No existen acaso los sueños? ¿No existen los sentimientos por el hecho de no tener cuerpo? Por lo tanto, la fantasía es una dimensión que permite conocer la realidad de sin inhibir la evocación creativa en los procesos cognitivos atendiendo a los sentidos, el pensamiento crítico o la ciencia (Rodari, 2004).

La importancia del fomento de la creatividad en la infancia es un elemento de gran importancia para el desarrollo personal del joven de cara al futuro. Educar en la creatividad es educar para el cambio y formar personas ricas en originalidad, flexibilidad, visión futura, iniciativa, confianza, preparadas para afrontar los obstáculos y problemas que se les van presentando en su vida. Así, la creatividad es una potencialidad que todo ser humano posee desde su nacimiento, que valora o inhibe según lo que vive en el transcurso de su existencia. (Fiorini, García-Ramírez, 2013)

Además si relacionamos todo lo anterior con la manipulación existente por parte de los medios de comunicación y los imperativos comerciales del menor como consumidor aumentará esta influencia en su día a día, generando una serie de ideas en ellos, que posiblemente condicionarán su actitud en un futuro en ciertas situaciones. Así, el cuento como instrumento lleva consigo una simbología que se desplegará a través de la palabra irradiando multiplicidad de significados. Esta irradiación invita al niño a un viaje de emociones, que le acerca a la imaginación literaria. A través de la lectura vivida se grabará una huella mnémica, que estará formada en nuestra memoria por el almacenamiento de imágenes afectivas junto con estructuras y formas de lo oral. (Pelegrin, 2010; Zerpa, 2012)

También a través de la biblioterapia se activa los procesos de escucha necesarios o imprescindibles para resolver cualquier situación conflictiva de manera satisfactoria y eficiente. Siendo ideal la escucha simpática (García-Ramírez, 2012).

\section{Objetivo}

Medir la imaginación creativa de dos contextos educativos diferentes.

\section{Método}

Se trata de un estudio exploratorio realizado a estudiantes de Educación Primaria en Granada, para medir la imaginación creativa.

\section{Participantes}

Los participantes del estudio han sido un total de 28 estudiantes (7 niños y 21 niñas) entre 9 y 11 años de edad, de un colegio ubicado en una zona marginada de Granada donde asisten estudiantes de familias con un nivel socioeconómico bajo. Por otra parte se constituyó un grupo control constituido por 14 estudiantes de las mismas características en cuanto a edad y género, pero que no participaron en el programa de bibliterapia. 


\section{Instrumento}

Se ha llevado a cabo la Prueba de Imaginación Creativa para Jóvenes, PIC-J, (Artola, Barraca, Martín, Mosteiro, Ancillo, Poveda, 2008) la cual consta de cuatro juegos, tres de ellos miden la creatividad verbal o narrativa y el cuarto la creatividad figurativa o gráfica.

Juego 1: Se muestra al sujeto un dibujo como herramienta para posteriormente redactar aquello que él valore pueda estar ocurriendo en la lámina mostrada. Este juego permite al niño expresar su curiosidad e imaginación y ha sido incluido en la PIC para analizar el potencial de los participantes a la hora de realizar hipótesis y pensar en términos de lo posible. A través de este juego podemos evaluar la facilidad para producir ideas, la producción divergente de unidades semánticas y la flexibilidad espontánea de su pensamiento, o capacidad para incorporar diversidad en las ideas generadas ante una situación relativamente estructurada.

Juego 2: Esta prueba hace referencia a los usos posibles de un objeto. Este juego se incluye como una medición de la posibilidad de los sujetos para liberar su espíritu y pensar de forma original. Además, con este juego podemos evaluar la capacidad de los sujetos para redefinir diversas problemáticas, es decir, la capacidad para crear usos, funciones y aplicaciones distintas utilidades fuera de las habituales, de agilizar la mente y generar nuevas exposiciones o significaciones ante objetos ya conocidos de cara a un nuevo uso o sentido. Con ello, podemos evaluar la capacidad del sujeto para producir un gran número de ideas diferentes sobre un tema, la capacidad de ofrecer soluciones diversas sobre algo concreto y la originalidad narrativa.

Juego 3: A través de esta prueba podemos valorar la capacidad de fantasía y la habilidad para aplicar ideas poco convencionales que posiblemente el sujeto no expresaría en situaciones más formales, así como la apertura y la propensión ante situaciones novedosas. Así, esta prueba permite evaluar la capacidad de penetración del sujeto o capacidad de ahondar en las experiencias. Por todo ello, a través de este juego podemos evaluar la fluidez creativa, la flexibilidad espontánea y la originalidad narrativa.

Juego 4: Se trata de una demostración de imaginación gráfica inspirada en ítems del test de Torrance. Con ella, la persona tiene que completar una serie de dibujos a partir de unos trazos dados y crear un título para cada uno de los mismos. Mediante esta prueba se mide la capacidad de la imaginación gráfica del sujeto. Con este juego podemos evaluar la capacidad de elaboración.

Finalmente, una vez realizada la prueba, para la corrección de la misma se han tenido en cuenta las siguientes variables:

1. Fluidez: Aptitud del sujeto para crear el mayor número de ideas.

2. Flexibilidad: Aptitud del sujeto para crear respuestas muy diversas, subordinadas a categorías o temas muy diversos.

3. Originalidad: Aptitud del sujeto a la hora de generar ideas alejadas de lo cierto, habitual o establecido.

4. Elaboración: Aptitud del sujeto para desarrollar, ampliar o embellecer las ideas.

5. Título: Aptitud del sujeto para elaborar una frase adecuada al dibujo más o menos sorprendente y no meramente descriptiva.

6. Detalles especiales: Aptitud del sujeto para asignar detalles como uniones, inversiones $\mathrm{y} / \mathrm{o}$ expansiones a los diversos dibujos. 


\section{Procedimiento}

Durante el primer semestre se implementa un programa de biblioterapia de siete sesiones en el colegio ubicado en la zona marginal de Granada. Las sesiones eran de dos horas semanales. Todas las sesiones realizadas estuvieron orientadas a trabajar la creatividad y la transmisión de valores.

Después de la última semana a los estudiantes participantes y a los del grupo control se les pasó el PIC-J. Posteriormente se procede a analizar los datos obtenidos.

\section{Resultados}

Ha continuación se muestran los datos obtenidos. El grupo experimental hace referencia a los estudiantes que participaron del programa de biblioterapia y el grupo control que hace referencia a los estudiantes no participantes.

Los resultados tanto para la imaginación narrativa como para la imaginación gráfica son significativamente más elevados para el grupo experimental que pare el grupo control.

La imaginación narrativa en los estudiantes del grupo experimental está en 85 percentiles mientras que en el grupo control está en 40 percentiles.

La imaginación gráfica en los estudiantes del grupo experimental está en 98 percentiles mientras que en el grupo control está en 30 percentiles.

La imaginación creativa en general en los estudiantes del grupo experimental está en 90 percentiles mientras que en el grupo control está en 40 percentiles.

Gráfica de imaginación narrativa, gráfica y general de los grupos experimental y control

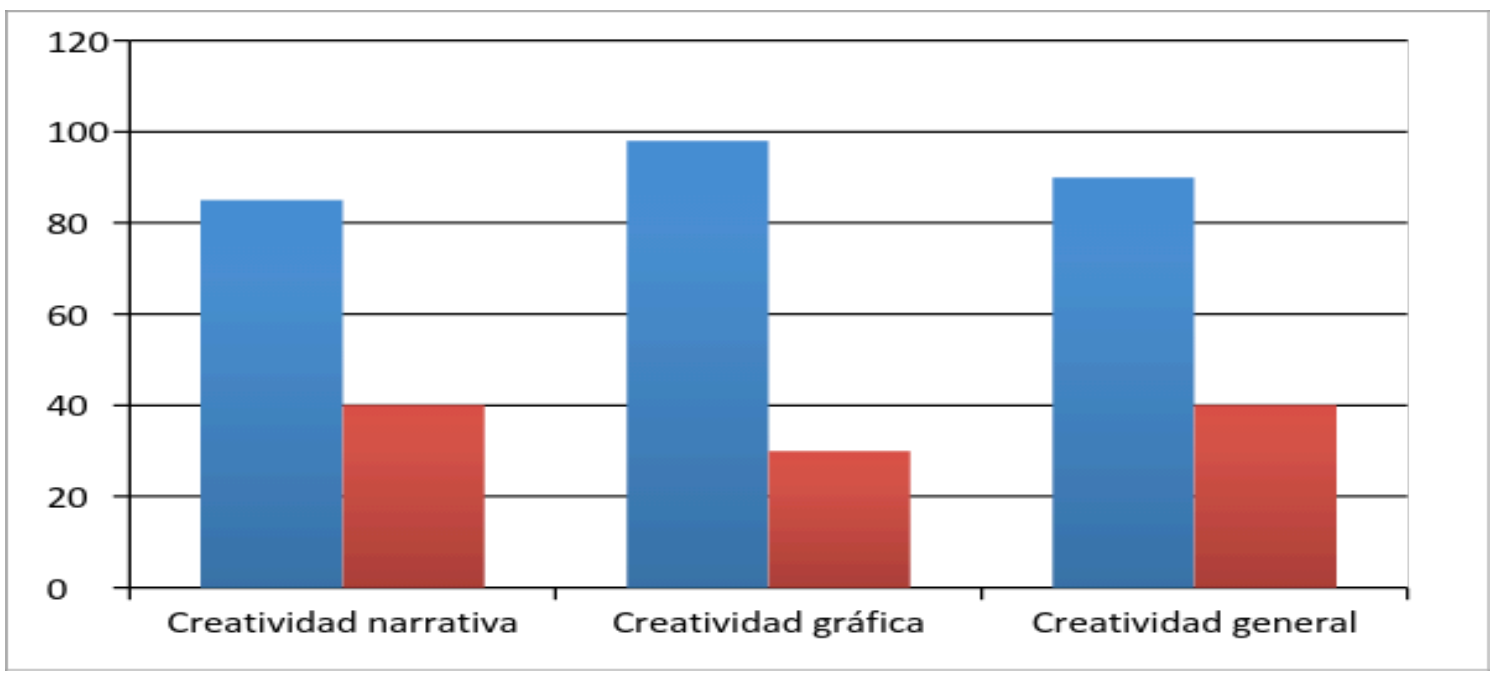

La gráfica muestra que las medias de los resultados de la creatividad narrativa, la creatividad gráfica y la creatividad general para el grupo control está por debajo de la media de 60 percentiles. Ese dato muestra como influye el contexto en el desarrollo de la creatividad en los menores que viven en situación socioeconómicamente precaria. 


\section{Discusión}

Considerando la lectura individual como una actividad placentera, paralelamente, encontramos la lectura en voz alta. A través de ella, en el ámbito de los niños podemos obtener grandes beneficios como trabajar la concentración, la comprensión, adquisición de nuevo vocabulario, desarrollar la imaginación, la capacidad de autoexpresión para poder expresar sus pensamientos e ideas. Con ella, podemos trabajar muchos campos dentro de la educación que con la propia lectura individual pueden pasar desapercibidos.

El uso de la lectura como terapia ha obtenido resultados positivos en diferentes contextos que van desde los centros penitenciarios a menores hospitalizados. La lectura como instrumento para trabajar la imaginación y la creatividad en la infancia es un elemento clave para el desarrollo general y la madurez de la persona.

Cada cuento lleva una historia a través de la cual se genera algún tipo de emoción en la persona. Se trata de páginas en las que las emociones florecen tras un personaje.

La importancia de la imaginación y la creatividad desde edades muy tempranas es una cuestión que ira vinculada al niño para su propia autoformación y desarrollo personal. De ahí la relevancia de trabajarla desde la infancia. La creatividad del sujeto crece y se desarrolla por las experiencias acumuladas con el tiempo, desarrollando la capacidad productiva y elaborada cuando la conciencia logra controlar y mediar racionalmente pasiones, sentimientos y emociones en su acción transformadora de la misma realidad.

Los datos obtenidos de la investigación realizada ponen de manifiesto como la biblioterapia influye y potencia la creatividad. Nos encontramos con jóvenes que inhiben sus expectativas por la delincuencia, los trabajos ilegales, las drogas, ..., el miedo que consecuentemente les genera la inhibición de su imaginación, de su creatividad. Estos aspectos han sido manifestados durante la implementación del programa de biblioterapia cuya imaginación quedaba. Por lo tanto se demuestra la necesidad de implementar programas que la imaginación de los menores e influyan en una mejora del comportamiento en general de cara a la inclusión social.

\section{Referencias}

Alves, M.H. (1982). A aplicação da Biblioterapia no processo de reintegração social. Revista Brasileira de Biblioteconomia e Documentação,15(19), 54-61.

Castaño, A.M. (2013). El alma de los cuentos. Instituto Andaluz de la Mujer.

Fiorini, M., García-Ramírez, JM. (2013). Cap. 5 :Técnicas de grupo y creatividad aplicadas en el ámbito universitario, en Villena, MD., Muñoz, A. Recursos para tutoría en el aula universitaria. Granada: Editorial Universidad de Granada.

García-Ramírez, J.M. (2012). La comunicación, clave de excelencia visible en la Educación Superior. Journal for Educators, Teachers and Trainers , 3, 25-36. http://www.ugr.es/ jett/pdf/vol03_02_jett_garcia-ramirez.pdf.

Gentile, S., Mesurado, B., \& Vignale, P. (2013). Resiliencia en familias: una intervención en contexto educativo de riesgo social. Psicología $y$ Psicopedagogía, 6(17). 
Pelegrin, A. M., \& Lacoma, M. (1982). La aventura de oír: cuentos y memorias de tradición oral. Madrid: Cincel.

Robinson, J. C. (2012). Bibliotherapy with Children. Techniques of Grief Therapy: Creative Practices for Counseling the Bereaved, 306, 34-46.

Rodari, G. (2004). La imaginación en la literatura infantil. Imaginaria: revista de literatura infantil y juvenil, 43(125), 1-6.

Zerpa, I. (2012). De cómo me hice narradora oral y cómo vivo en cada intento. Revista Venezolana de Estudios de La Mujer, 11(27), 78-90. 